\title{
Eficiência na absorção e utilização de nitrogênio e atividade enzimática em genótipos de milho ${ }^{1}$
}

\author{
Nitrogen uptake and utilization efficiency and enzymatic activity in maize genotypes
}

\author{
Lucimar Rodrigues de Oliveira ${ }^{2}$, Glauco Vieira Miranda ${ }^{2 *}$, Rodrigo Oliveira DeLima ${ }^{2}$, Roberto Fritsche-Neto ${ }^{2}$ e \\ João Carlos Cardoso Galvão
}

\begin{abstract}
RESUMO - O objetivo desse estudo foi investigar o emprego dos componentes da eficiência no uso de nitrogênio e das atividades das enzimas nitrato redutase e glutamina sintetase na seleção de genótipos de milho eficientes no uso de nitrogênio (N). Foram avaliados 10 genótipos de milho em estádio de V4 em condições de alto e baixo $\mathrm{N}$. $\mathrm{O}$ experimento foi composto por um fatorial 2 x 10 (dois níveis de $\mathrm{N}$ e 10 genótipos de milho) em delineamento inteiramente casualizados com três repetições. Os seguintes caracteres foram avaliados: as eficiências na absorção (EAbN), na utilização (EUtN) e no uso de $\mathrm{N}(\mathrm{EUsN})$ e as atividades das enzimas glutamina sintetase (GS) e nitrato redutase (NR). Para os caracteres que o efeito de genótipos foi significativo $(\mathrm{p} \leq 0,05)$ na análise de variância por nível de $\mathrm{N}$, as médias foram comparadas por meio do teste $\mathrm{t}(\mathrm{p} \leq 0,05)$. Os ganhos indiretos na EUsN e em seus componentes com seleção sobre as atividades das enzimas NR e GS foram estimados em baixo N. Conclui-se que em alto N: a EAbN é eficiente para discriminar genótipos de milho eficientes no uso de nitrogênio; em baixo N: as EAbN e EUtN são eficientes para discriminar genótipos de milho eficientes no uso de nitrogênio, a atividade de NR não é um bom parâmetro fisiológico para discriminar genótipos de milho eficientes no uso de nitrogênio, e a seleção sobre atividade da enzima GS possibilita a seleção indireta de genótipos de milho eficientes no uso de nitrogênio.
\end{abstract}

Palavras-chave: Absorção. Utilização. Enzima. Melhoramento genético. Seleção indireta.

\begin{abstract}
The aim of this study was to investigate the employment of components of the nitrogen efficiency use (NUE), and of the activities of the nitrate reductase and glutamine synthetase enzymes in the selection of nitrogen use efficient maize genotypes of maize. Ten maize genotypes at V4 stage were evaluated under high and low N. The experiment consisted of a $2 \times 10$ factorial (two levels of $\mathrm{N}$ and ten maize genotypes), in a randomized complete block design with three replicates. The following traits were evaluated: $\mathrm{N}$ uptake efficiency (NUpE), $\mathrm{N}$ utilization efficiency (NUtE) and $\mathrm{N}$ use efficiency (NUE), and activities of the glutamine synthetase (GS) and nitrate reductase (NR) enzymes. For traits which the effect of genotype was significant $(\mathrm{p} \leq 0.05)$ in the variance analysis for level of $\mathrm{N}$, the mean were compared using the t test $(\mathrm{p} \leq 0.05)$. The indirect gains in NUE and their components with selection over the activities of the enzymes NR and GS were estimated under low N. We conclude that: under high N, NupE is efficient to differentiate nitrogen use efficient maize genotypes; under low N, NupE and NUtE efficient to differentiate nitrogen use efficient maize genotypes, the activity of NR enzyme is not a good physiological parameter for differentiate nitrogen use efficient maize genotypes, and selection over activity of GS enzyme enables the indirect selection of nitrogen use efficient maize genotypes.
\end{abstract}

Key words: Absorption. Usage. Enzyme. Genetic enhancement. Indirect selection.

\footnotetext{
*Autor para correspondência

${ }^{1}$ Recebido para publicação em 08/08/2011; aprovado em 27/02/2013

Parte da Tese de Doutorado do primeiro autor apresentada ao Programa de Pós-Graduação em Fitotecnia da Universidade Federal de Viçosa

${ }^{2}$ Departamento de Fitotecnia, Universidade Federal de Viçosa, Av. Ph Rlfs sn, Viçosa-MG, Brasil, 36.571-000, lucimarroliveira@gmail.com, glaucovmiranda@ufv.br, rodrigoodelima@gmail.com, roberto.neto@ufv.br, jgalvao@ufv.br
} 


\section{INTRODUÇÃO}

No mundo, cerca de 160 milhões de hectares são cultivados anualmente com milho (FOOD AND AGRICULTURE ORGANIZATION OF THE UNITED NATIONS, 2011). Aproximadamente 50\% dessa área são cultivadas em condições edafoclimáticas tropicais, nas quais predominam condições de baixa fertilidade natural dos solos e ocorrência de secas (MONNEVEUX et al., 2005). Aliado a isso, o elevado custo dos fertilizantes tem inviabilizadoo uso desses pelos pequenos agricultores dessa região. Esses fatores fazem com que a disponibilidade de nitrogênio $(\mathrm{N})$, nesses solos, seja muito baixa, impedindo que a planta de milho expresse todo seu potencial genético (DoVALE; DeLIMA; FRITSCHE-NETO, 2012a).

O N é constituinte de vários compostos orgânicos nas plantas, como aminoácidos, ácidos nucleicos, proteínas, enzimas e clorofilas (TAIZ; ZEIGER, 2010). Em milho, ele é o nutriente exigido em maior quantidade e o que mais limita a produtividade de grãos (LEMAIRE; GASTAL, 1997). Segundo Araújo; Ferreira e Cruz (2004), a produtividade de grãos de milho aumentou linearmente com a elevação das doses de $\mathrm{N}$ aplicadas no solo. Além disso, o aumento na produtividade de milho no século passado foi associado com aumento da adubação nitrogenada (DUVICK, 1997).

A eficiência no uso de $\mathrm{N}$ (EUsN) permite as plantas atingirem altas produtividades com maior sustentabilidade (AHLGREN et al., 2008). A EUsN é definida como a razão entre a produtividade de grãos ou peso de parte aérea da planta seca por unidade de $\mathrm{N}$ disponível no solo (MOLL; KAMPRATH; JACKSON, 1982). Ela é composta pela eficiência na absorção de $\mathrm{N}$, que é a capacidade da planta em absorver N, e pela eficiência na utilização de N, que é a capacidade interna da planta de produzir grãos ou matéria seca por unidade de nutriente absorvida. Cultivares de milho mais eficientes no uso de $\mathrm{N}$ podem ser obtidos com melhoramento genético para eficiência na absorção e/ou na utilização de N (HIREL; BERTIN; QUILLERÉ, 2001; GALLAIS; HIREL, 2004; SOUZA et al., 2008). Entretanto, DoVale et al. (2012b) avaliaram linhagens e híbridos de milho em estádio de V6 e concluíram que, independente da disponibilidade de $\mathrm{N}$, a eficiência na absorção de $\mathrm{N}$ foi mais importante para EUsN do que a eficiência na utilização. Assim, ambas os componentes da EUsN devem ser considerados na seleção de genótipos mais EUsN com maior peso para eficiência na absorção.

Entre os caracteres fisiológicos associados com EUsN em milho, destacam-se a atividade das enzimas nitrato redutase (NR) e glutamina sintetase (GS), que podem ser usadas na seleção de cultivares mais EUsN (HIREL et al., 2007; MACHADO; SODEK; FERNANDES, 2001). A NR é a enzima mais importante no processo de redução e assimilação de nitrato pelas plantas (PURCINO et al., 1994). A baixa atividade dela é a principal limitação à absorção de N em algumas plantas (LEA et al., 1997), e sua atividade depende principalmente da luz e do contínuo suprimento de nitrato através do xilema (KAWACHI et al., 2002). A GS é importante no processo de incorporação do $\mathrm{N}$, pois catalisa a reação de incorporação do amônio ao glutamato resultando em glutamina (NELSON; COX, 2010). Deste modo, a baixa atividade dessa enzima impede que as plantas expressem seu máximo potencial produtivo (UNNO et al., 2006).

Assim, o objetivo desse trabalho foi investigar o emprego dos componentes da eficiência no uso de nitrogênio e das atividades das enzimas nitrato redutase e glutamina sintetase na seleção de genótipos de milho eficientes no uso de nitrogênio.

\section{MATERIAL E MÉTODOS}

Uma variedade de polinização aberta, a UFVM 100, um híbrido simples, o BRS 3060 e oito linhagens de milho proveniente do banco de germoplasma do programa de melhoramento de milho da Universidade Federal de Viçosa (UFV), Programa Milho ${ }^{\circledR}$, foram avaliados em casa de vegetação pertencente ao Departamento de Fitotecnia da UFV, em abril de 2009. Sementes de todos os genótipos foram esterilizadas por um minuto em uma solução de $0,5 \%$ de hipoclorito de sódio e, posteriormente, lavadas duas vezes com água deionizada. Após a lavagem, as sementes dos dez genótipos de milho foram semeadas em vasos opacos de polietileno preenchidos com $5,0 \mathrm{dm}^{3}$ de substrato. $\mathrm{O}$ substrato utilizado foi constituído por uma mistura de areia lavada em água deionizada e vermiculita inerte, na proporção de 1:1, conforme Walker, Jaramillo e Lynch (2006). Foram semeadas seis sementes de cada genótipo por vaso. Após a emergência das plântulas, foi realizado um desbaste e deixadas três plantas vaso ${ }^{-1}$.

Para adubação das plantas, utilizou-se a solução nutritiva descrita por Chun et al. (2005), que continha, no alto nível de $\mathrm{N}$ : $2,0 \mathrm{mmol} \mathrm{L} \mathrm{L}^{-1}$ de $\mathrm{Ca}\left(\mathrm{NO}_{3}\right)_{2} ; 0,75$ mmol L-1 de $\mathrm{K}_{2} \mathrm{SO}_{4} ; 0,65 \mathrm{mmol} \mathrm{L}^{-1}$ de $\mathrm{MgSO}_{4} ; 0,1 \mathrm{mmol} \mathrm{L}^{-1}$ de $\mathrm{KCl} ; 0,25 \mathrm{mmol} \mathrm{L}^{-1}$ de $\mathrm{KH}_{2} \mathrm{PO}_{4} ; 1 \times 10^{-3} \mathrm{mmol} \mathrm{L}^{-1} \mathrm{de}$ $\mathrm{H}_{3} \mathrm{BO}_{3} ; 1 \times 10^{-3} \mathrm{mmol} \mathrm{L}^{-1}$ de $\mathrm{MnSO}_{4} ; 1 \times 10^{-4} \mathrm{mmol} \mathrm{L}^{-1} \mathrm{de}$ $\mathrm{CuSO}_{4} ; 1 \times 10^{-3} \mathrm{mmol} \mathrm{L}^{-1}$ de $\mathrm{ZnSO}_{4} ; 5 \times 10^{-6} \mathrm{mmol} \mathrm{L}^{-1} \mathrm{de}$ $\left(\mathrm{NH}_{4}\right)_{6} \mathrm{Mo}_{7} \mathrm{O}_{24}$; e $0,1 \mathrm{mmol} \mathrm{L}^{-1}$ de Fe-EDTA. No baixo $\mathrm{N}$, a solução continha: $0,2 \mathrm{mmol} \mathrm{L} \mathrm{L}^{-1}$ de $\mathrm{Ca}\left(\mathrm{NO}_{3}\right)_{2}$, ou seja, a concentração de $\mathrm{N}$ foi dez vezes inferior do que a contida no alto N. O $\mathrm{Ca}^{2+}$ foi compensado pela adição de $\mathrm{CaCl}_{2}$ na solução. Em todo experimento, foi fornecido $0,250 \mathrm{~L} \mathrm{vaso}^{-1}$ de solução nutritiva a cada dois dias, a partir do sétimo dia após a emergência das plântulas. O experimento foi composto por um fatorial 
2 x 10 (dois níveis de $\mathrm{N}$ e 10 genótipos de milho) em delineamento inteiramente casualizado com três repetições. A unidade experimental foi constituída de um vaso com três plantas.

Próximo à coleta das plantas, aproximadamente 25 dias após a germinação, retirou-se a terceira folha completamente desenvolvida de todas as plantas de cada genótipo. Dessas folhas, foram retirados nove discos uniformes foliares de um $\mathrm{cm}$ de diâmetro para determinar a atividade da GS. Na determinação da atividade da GS, foi utilizado o método proposto por Elliott (1953). Posteriormente, as folhas foram submersas em água com gelo e levadas ao laboratório para determinação da atividade da NR por meio de ensaio in vivo (DA MATTA; AMARAL; RENA, 1999). As coletas de folhas para determinação da atividade das enzimas NR e GS foram realizados entre 7 e $8 \mathrm{~h}$ da manhã. A atividade da NR foi expressa em $\mu$ moles de $\mathrm{NO}_{2}$ por grama de matéria fresca por hora ( $\mu$ moles de $\mathrm{NO}_{2}^{-} \mathrm{g}^{-1} \mathrm{MF} \mathrm{h}^{-1}$ ). A atividade da GS foi expressa em $\mu$ moles de glutamil-hidroxamato (GGH) produzido por grama de matéria fresca por minuto ( $\mu$ moles GGH g-1 $\left.\mathrm{MF} \mathrm{min}^{-1}\right)$.

As plantas foram coletadas no estádio vegetativo V4 (quatro folhas completamente desenvolvidas), aproximadamente 28 dias após a germinação. No momento da coleta das plantas, a parte aérea foi separada do sistema radicular e ambas as partes foram acondicionadas em sacos de papel. Posteriormente, procedeu-se a secagem de ambas as partes em estufa de circulação forçada de ar a $60{ }^{\circ} \mathrm{C}$ por 72:00 horas, até atingirem peso constante. Após a secagem das plantas, o peso de plantas inteiras secas (raiz + parte aérea) (PPS) foi determinado.

Para a quantificação de $\mathrm{N}$ na parte aérea das plantas, foram extraídas amostras de $0,2 \mathrm{~g}$ da parte aérea das plantas secas de cada genótipo. Em seguida, foram feitas a digestão, a destilação e a titulação, conforme Bremner e Mulvaney (1982). Após isso, calculou-se o teor de $\mathrm{N}$ em cada amostra e, então, estimou-se o conteúdo de $\mathrm{N}$ total na parte aérea de todas as plantas. Com o conteúdo de $\mathrm{N}$, as eficiências na absorção $(\mathrm{EAbN})$, eficiência na utilização (EUtN) e eficiência no uso de N (EUsN) foram obtidas, de acordo com MOLL; KAMPRATH; JACKSON (1982):

$\mathrm{EAbN}\left(\mathrm{mg} \mathrm{Mg}^{-1}\right)=\mathrm{CNT} / \mathrm{NAV}$

$\operatorname{EUtN}\left(\mathrm{mg} \mathrm{Mg}^{-1}\right)=\mathrm{PPS} / \mathrm{CNT}$

EUsN $\left(\mathrm{mg} \mathrm{Mg}^{-1}\right)=\mathrm{PPS} / \mathrm{NAV}=\mathrm{EUtN} \times \mathrm{EAbN}$ em que: CNT é o conteúdo de $\mathrm{N}$ total de todas as plantas do vaso; NAV é a quantidade de $\mathrm{N}$ total aplicado em cada vaso durante todo o experimento; PPS é o peso de todas as plantas secas do vaso (raiz + parte aérea).

Após a coleta dos dados, eles foram submetidos à análise de variância individual, em cada nível de $\mathrm{N}$, e as médias e os quadrados médios dos resíduos de análise em cada nível de $\mathrm{N}$ foram usados para fazer a análise de variância fatorial. $\mathrm{Na}$ análise de variância por nível de $\mathrm{N}$, o efeito de genótipo foi considerado fixo, conforme o modelo estatístico (PIMENTEL-GOMES, 2009):

$\mathrm{Y}_{\mathrm{ij}}=\mu+\mathrm{g}_{\mathrm{i}}+\mathrm{e}_{\mathrm{ij}}$

em que: $\mathrm{Y}_{\mathrm{ij}}$ é o valor observado para o carácter em estudo referente ao i-ésimo genótipo na j-ésima repetição; $\mu$ é a média de todas as unidades experimentais para o carácter em estudo; $\mathrm{g}_{\mathrm{i}}$ é o efeito do genótipo i ( $\left.\mathrm{i}=1,2, \ldots, 10\right)$ no valor observado $\mathrm{Y}_{\mathrm{ij}}$; $\mathrm{e}_{\mathrm{ij}} \mathrm{o}$ erro aleatório associado à observação $\mathrm{Y}_{\mathrm{ij}}, \mathrm{e}_{\mathrm{ij}} \sim \mathrm{NID}\left(0, \sigma^{2}\right)$.

Após a realização da análise por nível de $\mathrm{N}$, os caracteres que apresentaram variâncias residuais homogêneas pelo teste de Bartlett (1937) $(\mathrm{p} \leq 0,05)$ foram submetidos à análise de variância fatorial. $\mathrm{Na}$ análise de variância fatorial todos os efeitos foram considerados fixos, exceto o erro, conforme o modelo estatístico (PIMENTEL-GOMES, 2009):

$\mathrm{Y}_{\mathrm{ijk}}=\mu+\alpha_{\mathrm{i}}+\beta_{\mathrm{j}}+(\alpha \beta)_{\mathrm{ij}}+\mathrm{e}_{\mathrm{ijk}}$

em que: $\mathrm{Y}_{\mathrm{ijk}}$ é o valor observado para a carácter em estudo referente a k-ésima repetição da combinação do i-ésimo nível do fator A (genótipos) com o j-ésimo nível do fator $\mathrm{B}$ (níveis de $\mathrm{N}$ ); $\mu$ é a média de todas as unidades experimentais para o carácter em estudo; é o efeito do i-ésimo genótipo ( $\mathrm{i}=1,2, \ldots, 10)$ no valor observado $\mathrm{Y}_{\mathrm{ijk}} ; \beta_{\mathrm{j}}$ é o efeito do j-ésimo nível de $\mathrm{N}(\mathrm{j}=1,2)$ no valor observado $\mathrm{Y}_{\mathrm{ijk}} ;(\alpha \beta)_{\mathrm{ij}}$ é o efeito da interação do i-ésimo genótipo com j-ésimo nível de $\mathrm{N}$ no valor observado $\mathrm{Y}_{\mathrm{ijk}}$; $\mathrm{e}_{\mathrm{ijk}}$ é erro aleatório associado à observação $\mathrm{Y}_{\mathrm{ijk}}, \mathrm{e}_{\mathrm{ijk}} \sim \mathrm{NID}$ $\left(0, \sigma^{2}\right)$.

Os caracteres que apresentaram efeito de genótipos significativo na análise de variância por nível de $\mathrm{N}$ tiveram as médias comparadas por meio do teste $\mathrm{t}(\mathrm{p} \leq 0,05)$. As correlações fenotípicas entre as atividades das enzimas $\mathrm{NR}$ e GS e as eficiências de $\mathrm{N}$ foram estimadas e testadas a 1 e a $5 \%$ de probabilidade pelo teste t. Além disso, foram estimados os ganhos indiretos nas eficiências de $\mathrm{N}$ com seleção realizada nas atividades das enzimas NR e GS, em baixo N. As estimativas dos ganhos indiretos na eficiência no uso de $\mathrm{N}$ e seus componentes foram obtidos segundo equação 6: 
$\mathrm{GS}_{\mathrm{Ef}(\mathrm{En})}=\hat{\mathrm{H}}_{\mathrm{GEf}}^{2} \mathrm{DS}_{\mathrm{Ef}(\mathrm{En})}$

em que: $\mathrm{GS}_{\mathrm{Ef(En)}}$ é a estimativa do ganho indireto na eficiência de $\mathrm{N}$ (Ef), quando a seleção é praticada sobre a atividade da enzima (En); $\hat{H}^{2}{ }_{\text {GEf }}$ é a estimativa do coeficiente de determinação genotípico para eficiência (Ef) de $\mathrm{N}$ considerada; $\mathrm{DS}_{\mathrm{Ef}(\mathrm{En})}$ é diferencial de seleção indireto, obtido pela diferença entre a média dos indivíduos selecionados para eficiência de $\mathrm{N}$ (Ef), cuja a superioridade foi identificada pelo bom desempenho em relação a atividade da enzima (En) e a média original dos genótipos em relação a Ef. Para os 10 genótipos de milho avaliados foram considerados a seleção dos quatro genótipos superiores para a atividade das enzimas GS e NR e estimados os ganhos indiretos nas três eficiências de $\mathrm{N}$.

As análises genético-estatísticas foram realizadas com o auxílio do programa estatístico computacional Statistical Analysis System (SAS), versão 9.1 (SAS Institute, 2003).

\section{RESULTADOS E DISCUSSÃO}

Em ambos os níveis de $\mathrm{N}$, foi verificada existência de variabilidade genotípica entre os genótipos de milho para eficiência no uso (EUsN) e na absorção de N (EAbN) $(\mathrm{p} \leq 0.01)$ (Tabela. 1). Em alto $\mathrm{N}$, não foi verificada variabilidade genotípica para eficiência na utilização de $\mathrm{N}$ (EUtN) e para atividade das enzimas nitrato redutase (NR) e glutamina sintetase (GS) ( $>>0.05)$. Machado, Sodek e Fernandes (2001) também não encontraram diferença significativa entre variedades de milho para EUtN em alto $\mathrm{N}$, avaliadas em alto e baixo N. Assim, em condições de alto $\mathrm{N}$, parece que a variabilidade genotípica para EUsN é função apenas da diferença na EAbN (GALLAIS, HIREL, 2004; SOUZA et al., 2008). Nessas condições, é provável que uma maior EAbN esteja associada à presença de transportadores de nitrato de alta afinidade na membrana celular de raízes de milho (LEA; AZEVEDO, 2007).

Em baixo $\mathrm{N}$, a existência de variabilidade genotípica entre os genótipos de milho para todos os caracteres (Tabela 1), indica que, nessas condições, além da planta ser eficiente em absorver o escasso $\mathrm{N}$ do solo, ela é eficiente em utilizá-lo canalizando-o para a produção de biomassa e grãos de milho (HIREL et al., 2007). Deste modo, a maior eficiência na absorção de nitrato, a partir de baixas concentrações na solução externa, pode ser uma indicação de adaptação das plantas mais eficientes no uso de $\mathrm{N}$ às condições de baixo $\mathrm{N}$ (COQUE; GALLAIS, 2007).

As estimativas do coeficiente de determinação genotípico $\left(\hat{\mathrm{H}}_{\mathrm{G}}^{2}\right)$, que expressa a proporção da variância fenotípica devido a variabilidade genotípica entre as médias de tratamentos (CRUZ, 2005), foram influenciadas

Tabela 1 - Resumo da análise de variância individual, médias, coeficientes de variação $\left(\mathrm{CV}_{\%}\right)$ e estimativas do coeficiente de determinação genotípico $\left(\hat{\mathrm{H}}_{\mathrm{GEf}}^{2} \%\right)$ para os caracteres eficiência na absorção $\left(\mathrm{EAbN}, \mathrm{mg} \mathrm{mg}^{-1}\right)$, na utilização $\left(\mathrm{EUtN}, \mathrm{mg} \mathrm{mg}^{-1}\right)$ e no uso de $\mathrm{N}$ (EUsN, mg mg ${ }^{-1}$ ) e atividade das enzimas nitrato redutase ( $\mathrm{NR}, \mu$ moles de $\mathrm{NO}_{2}^{-} \mathrm{g}^{-1} \mathrm{MF} \mathrm{h}^{-1}$ ) e glutamina sintetase (GS, $\mu$ moles $\left.\mathrm{GGH} \mathrm{g}^{-1} \mathrm{MF} \mathrm{min}^{-1}\right)$ avaliados em 10 genótipos de milho em dois níveis de nitrogênio

\begin{tabular}{|c|c|c|c|c|c|c|}
\hline \multirow{2}{*}{ Fonte de variação } & \multirow{2}{*}{ GL } & \multicolumn{5}{|c|}{ Quadrado Médio } \\
\hline & & EAbN & EUtN & EUsN & NR & GS \\
\hline \multicolumn{7}{|c|}{ Alto $\mathrm{N}$} \\
\hline Genótipos & 9 & $0,03 * *$ & $10,77^{\text {ns }}$ & $19,40 * *$ & $0,24^{\mathrm{ns}}$ & $8,85^{\text {ns }}$ \\
\hline Resíduo & 20 & 0,00 & 7,15 & 3,68 & 0,30 & 5,95 \\
\hline Média & & 0,28 & 24,31 & 6,98 & 1,18 & 12,33 \\
\hline $\mathrm{CV}(\%)$ & & 27,47 & 11,00 & 27,50 & 46,32 & 19,77 \\
\hline$\hat{\mathrm{H}}_{{ }_{\mathrm{G}}}{ }$ & & 82,58 & 33,64 & 80,99 & 0,00 & 32,72 \\
\hline \multicolumn{7}{|c|}{ Baixo N } \\
\hline Genótipos & 9 & $0,19 * *$ & $105,37 * *$ & $729,59 * *$ & $0,11^{*}$ & $39,86^{* *}$ \\
\hline Resíduo & 20 & 0,03 & 24,67 & 97,89 & 0,03 & 6,91 \\
\hline Média & & 0,926 & 44,80 & 42,60 & 0,38 & 13,48 \\
\hline $\mathrm{CV}(\%)$ & & 20,71 & 11,08 & 23,22 & 49,46 & 19,51 \\
\hline$\hat{\mathrm{H}}_{{ }_{\mathrm{G}}}{ }$ & & 81,42 & 76,58 & 86,58 & 69,60 & 82,64 \\
\hline
\end{tabular}

${ }^{* *, *, \text { ns }}$ significativo a $1 \%$, a $5 \%$ de probabilidade e não significativo a $5 \%$ de probabilidade pelo teste $\mathrm{F}$, respectivamente 
pela disponibilidade de $\mathrm{N}$ (Tabela 1). Com exceção da $\hat{\mathrm{H}}^{2}{ }_{\mathrm{G}}$ para EAbN, cuja magnitude foi semelhante nos dois níveis de $\mathrm{N}$, para os demais caracteres, as $\hat{\mathrm{H}}^{2}{ }_{\mathrm{G}}$ em alto $\mathrm{N}$ foram inferiores às obtidas em baixo $\mathrm{N}$. Em alto $\mathrm{N}$, as $\hat{\mathrm{H}}_{\mathrm{G}}{ }_{\mathrm{G}}$ foram 56,07 e $60,41 \%$ inferiores às obtidas em baixo $\mathrm{N}$ para EUtN e GS, respectivamente, e nula para atividade de NR. Esses resultados são contraditórios aos encontrados em milho avaliado em condições de estresse abiótico, nas quais geralmente as estimativas de herdabilidade, parâmetro semelhante ao coeficiente de determinação genotípica, em baixo $\mathrm{N}$, são inferiores às estimativas obtidas em alto $\mathrm{N}$ para produtividade de grãos (HEINZ et al., 2012; PRESTERL et al., 2003; SOARES et al., 2011), caracteres morfológicos da planta (BERTIN; GALLAIS, 2000) e eficiência no uso de $\mathrm{N}$ e seus componentes em milho (DoVALE et al., 2012b).

A EUsN não apresentou variâncias residuais homogêneas pelo teste de Bartlett (1937) $(\mathrm{p} \leq 0,05)$ e, consequentemente, não foi submetida à análise de variância fatorial. Nessa, o efeito de níveis de $\mathrm{N}$ foi significativo $(\mathrm{p} \leq 0,01)$ para os caracteres avaliados, a exceção da atividade de GS (Tabela 2). Isso demonstra que para esses caracteres a diferença de disponibilidade de $\mathrm{N}$ foi eficiente para avaliar a resposta do milho quanto à adubação nitrogenada e reprodução do estresse abiótico para a planta, exceto para a atividade da GS.

A interação genótipos $(G)$ x níveis de $\mathrm{N}$ foi significativa para EAbN, EUtN e atividade de GS. Esses resultados indicam que, à exceção de atividade de NR, a seleção de genótipos de milhos superiores para esses caracteres deve ser realizada em ambientes específicos. Esses resultados estão de acordo com os relatados na literatura com avaliação de genótipos de milho em estádio de plântulas. DoVale et al. (2012b) usaram a mesmas doses de $\mathrm{N}$ para avaliar linhagens e híbridos de milho em estádio de V6 e verificaram presença de interação $\mathrm{G} \times \mathrm{N}$ significativa para EAbN e EUtN. Além disso, Majerowicz et al. (2002) relataram ausência de interação $\mathrm{G} \times \mathrm{N}$ para atividade de NR avaliada em populações de milho no estádio de V6 em dois níveis de N. Assim, parece que os genes que controlam a expressão das eficiências de $\mathrm{N}$ e da atividade de GS em milho são expressos em função da disponibilidade de $\mathrm{N}$ no solo (GALLAIS; HIREL, 2004; HIREL; BERTIN; QUILLERÉ, 2001; SOUZA et al., 2008), e que a diferença de disponibilidade de $\mathrm{N}$ no solo não foi suficiente para alterar comportamento relativo médio da atividade de NR.

Quando se avalia um experimento em apenas um local, a variância genotípica está inflacionada pela interação genótipos $\mathrm{x}$ ambientes. $\mathrm{Na}$ análise conjunta, o componente da interação é isolado (RAMALHO; FERREIRA; OLIVEIRA, 2012). Para esse conjunto de genótipos de milho, o efeito de genótipos foi significativo $(\mathrm{p} \leq 0,01)$ para a eficiência no uso de $\mathrm{N}$ e seus componentes e para atividade de GS, o que mostra que há variabilidade genotípica entre os genótipos de milho para esses caracteres (Tabela 2). Quanto à precisão experimental, o coeficiente de variação (CV\%) não foi influenciado pela disponibilidade de $\mathrm{N}$ no solo, e, apesar da presença de alguns valores altos, esses estão dentro do aceitável para trabalhos desta natureza (DoVALE et al., 2012b; FRITSCHE-NETO et al., 2010; MACHADO; SODEK; FERNANDES, 2001; MAIA et al., 2011; MAJEROWICZ et al., 2002; MAIA et al., 2011).

De acordo com análise de variância individual, em alto $\mathrm{N}$, houve variabilidade genotípica apenas para EAbN e EUsN. Logo, apenas as médias desses caracteres foram comparadas pelo teste $\mathrm{t}(\mathrm{p} \leq 0,05)$. Enquanto que em baixo $\mathrm{N}$, as médias de todos os caracteres foram comparadas pelo teste $\mathrm{t}(\mathrm{p} \leq 0,05)$, pois houve variabilidade genotípica para todos eles. Em ambos os níveis de N, houve diferença significativa $(\mathrm{p} \leq 0.05)$ pelo teste $t$ entre as médias dos genótipos para todos os caracteres. A média de $\mathrm{EAbN}$, em baixo N, foi 3,18 vezes superior à obtida em alto $\mathrm{N}$ (Tabela 3). Para a EUsN, essa

Tabela 2 - Resumo da análise de variância fatorial para os caracteres eficiência na absorção (EAbN, $\left.\mathrm{mg} \mathrm{mg}^{-1}\right)$, na utilização (EUtN, mg mg-1) e no uso de $\mathrm{N}\left(\mathrm{EUsN}, \mathrm{mg} \mathrm{mg}^{-1}\right.$ ) e atividade das enzimas nitrato redutase (NR, $\mu$ moles de $\mathrm{NO}_{2}^{-} \mathrm{g}^{-1} \mathrm{MF} \mathrm{h}^{-1}$ ) e glutamina sintetase (GS, $\mu$ moles GGH g ${ }^{-1} \mathrm{MF} \mathrm{min}^{-1}$ ) avaliados em 10 genótipos de milho em dois níveis de nitrogênio

\begin{tabular}{lccccc}
\hline \multirow{2}{*}{ Fonte de Variação } & \multirow{2}{*}{ GL } & \multicolumn{4}{c}{ Quadrado Médio } \\
\cline { 3 - 6 } & & EAbN & EUtN & NR & GS \\
\hline Linhagens (L) & 9 & $0,19^{* *}$ & $47,51^{* *}$ & $0,27^{\mathrm{ns}}$ & $32,25^{* *}$ \\
Níveis de N (N) & 1 & $6,08^{* *}$ & $6301,53^{* *}$ & $9,62^{* *}$ & $19,64^{\mathrm{ns}}$ \\
Lx N & 9 & $0,03^{*}$ & $68,64^{* *}$ & $0,08^{\mathrm{ns}}$ & $16,46^{*}$ \\
Resíduo & 40 & 0,02 & 15,91 & 0,16 & 6,43 \\
\hline Média Geral & & 0,6 & 34,56 & 0,78 & 12,9 \\
CV $(\%)$ & 24,00 & 11,00 & 52,00 & 19,00 \\
\hline
\end{tabular}

${ }^{* *, *, \text { ns }}$ significativo a $1 \%$, a $5 \%$ de probabilidade e não significativo a $5 \%$ de probabilidade pelo teste $\mathrm{F}$, respectivamente 
Tabela 3 - Médias de eficiência na absorção (EAbN, $\mathrm{mg} \mathrm{mg}^{-1}$ ) e no uso de $\mathrm{N}$ (EUsN, $\mathrm{mg} \mathrm{mg}^{-1}$ ) em alto $\mathrm{N}$ e de eficiência na absorção (EAbN, $\mathrm{mg} \mathrm{mg}^{-1}$ ), na utilização (EUtN, $\mathrm{mg} \mathrm{mg}^{-1}$ ) e no uso de $\mathrm{N}\left(\mathrm{EUsN}, \mathrm{mg} \mathrm{mg}^{-1}\right)$ e de atividade das enzimas nitrato redutase (NR, $\mu$ moles de $\mathrm{NO}_{2}{ }^{-} \mathrm{g}^{-1} \mathrm{MF} \mathrm{h}^{-1}$ ) e glutamina sintetase (GS, $\mu$ moles GGH g${ }^{-1} \mathrm{MF} \mathrm{min}^{-1}$ ) em baixo $\mathrm{N}$ avaliados em 10 genótipos de milho

\begin{tabular}{|c|c|c|c|c|c|c|c|}
\hline \multirow{2}{*}{ Genótipo } & \multicolumn{2}{|c|}{ Alto $\mathrm{N}$} & \multicolumn{5}{|c|}{ Baixo N } \\
\hline & EAbN & EUsN & EAbN & EUtN & EUsN & NR & GS \\
\hline BRS 3060 & 0,44 & 9,16 & 1,25 & 53,43 & 66,84 & 0,15 & 15,53 \\
\hline UFVM 100 & 0,41 & 9,90 & 1,09 & 51,45 & 56,35 & 0,34 & 15,56 \\
\hline L1 & 0,36 & 8,68 & 1,08 & 47,99 & 52,49 & 0,45 & 18,63 \\
\hline $\mathrm{L} 2$ & 0,34 & 9,10 & 1,11 & 45,31 & 49,87 & 0,09 & 18,9 \\
\hline L3 & 0,30 & 6,86 & 1,08 & 44,23 & 47,58 & 0,75 & 11,94 \\
\hline L4 & 0,29 & 7,77 & 0,87 & 45,56 & 38,5 & 0,42 & 8,73 \\
\hline L5 & 0,22 & 5,92 & 0,9 & 42,29 & 38,07 & 0,39 & 9,69 \\
\hline L6 & 0,29 & 6,74 & 0,81 & 46,25 & 37,59 & 0,23 & 12,18 \\
\hline L7 & 0,17 & 3,71 & 0,68 & 38,5 & 26,15 & 0,39 & 13,86 \\
\hline L8 & 0,08 & 1,98 & 0,38 & 33,05 & 12,54 & 0,6 & 9,74 \\
\hline Média & 0,29 & 6,98 & 0,92 & 44,8 & 42,6 & 0,38 & 13,48 \\
\hline DMS-t ${ }_{(5 \%)}$ & 0,14 & 3,27 & 0,32 & 8,46 & 16,85 & 0,32 & 4,47 \\
\hline
\end{tabular}

diferença foi maior, em baixo $\mathrm{N}$ ela foi 6,41 vezes superior à obtida em alto $\mathrm{N}$. Estes resultados são semelhantes aos relatados na literatura por alguns autores. Nesses estudos, em combinações híbridas de milho avaliadas em condições de campos em diferentes níveis de $\mathrm{N}$, as médias para EUsN e seus componentes em baixo $\mathrm{N}$ foram superiores às médias obtidas em alto N (SOUZA et al., 2008; URIBELARREA; MOOSE; BELOW, 2007). Em outro estudo, DoVale et al. (2012b) também encontram que as médias para EUsN e seus componentes, em baixo $\mathrm{N}$, foram superiores às médias dos genótipos obtidas em alto $\mathrm{N}$.

Os cultivares UFVM 100 e BRS 3060 tiveram bom comportamento para quase todos oscaracteres avaliados, à exceção da atividade de NR em baixo N (Tabela 3). As estimativas de correlações entre as médias das EAbN e EUsN em alto com as médias dessas mesmas eficiências em baixo $\mathrm{N}$ foram de 0,936 e 0,929 , respectivamente. Mas, os genótipos com maiores médias para atividade de NR não foram os superiores para eficiência no uso de $\mathrm{N}$ e seus componentes. Por exemplo, a L8 teve a segunda maior média para NR, mas as menores médias para eficiência no uso de $\mathrm{N}$ e seus componentes. Outro exemplo, é o híbrido BRS 3060 que teve as maiores médias para as três eficiências em baixo $\mathrm{N}$ e EAbN em alto $\mathrm{N}$, mas a segunda menor média para atividade da enzima NR. Em relação à outra enzima, as linhagens L2 e L1 tiveram as maiores médias para atividade de GS, as quais não diferiram entre si pelo teste $t(p>0,05)$. Além disso, a L1 e a L2 são as linhagens mais eficientes no uso de $\mathrm{N}$ em alto e baixo $\mathrm{N}$, respectivamente.
Diante dos resultados das análises de variâncias individuais por nível de $\mathrm{N}$, em que as atividades $\mathrm{NR}$ e GS não apresentaram diferença significativa $(p>0,05)$ em alto $\mathrm{N}$, as relações entre atividades das enzimas e eficiências de $\mathrm{N}$ foram estudadas apenas em baixo $\mathrm{N}$. As correlações entre atividade de GS e as eficiências de $\mathrm{N}$ foram significativas pelo teste $\mathrm{t}(\mathrm{p}<0,05)$, positivas e de média magnitude (Tabela 4). Quanto à atividade da NR, essa correlacionou negativamente com eficiência no uso de N e seus componentes. Hirel, Bertin e Quilleré (2001) avaliaram linhagens de milho em dois níveis de $\mathrm{N}$ e encontraram correlações positivas entre a atividade de GS e caracteres agronômicos, independente do nível de N, e correlações negativas entre atividade de NR e caracteres agronômicos em baixo N. Em estudos de mutantes de

Tabela 4 - Estimativas de correlações fenotípicas entre as eficiências na absorção (EAbN), na utilização (EUtN, $\mathrm{mg} \mathrm{mg}^{-1}$ ) e no uso de $\mathrm{N}$ (EUsN, $\mathrm{mg} \mathrm{mg}^{-1}$ ) e as atividades das enzimas nitrato redutase ( $\mathrm{NR}, \mu$ moles de $\mathrm{NO}_{2}^{-} \mathrm{g}^{-1} \mathrm{MF} \mathrm{h}^{-1}$ ) e glutamina sintetase (GS, $\mu$ moles GGH g ${ }^{-1} \mathrm{MF} \mathrm{min}^{-1}$ ) avaliados em 10 genótipos de milho em baixo $\mathrm{N}$

\begin{tabular}{llll}
\hline Carácter & EAbN & EUtN & EUsN \\
\hline NR & $-0,38^{*}$ & $-0,50 * *$ & $-0,43^{*}$ \\
GS & $0,60 * *$ & $0,50 * *$ & $0,61 * *$ \\
\hline
\end{tabular}

${ }^{* *}, *$, ns Significativo a $1 \%$, a $5 \%$ e não significativo a $5 \%$ pelo teste $\mathrm{t}$, respectivamente 
milho e arroz, foi demonstrado que a GS é necessária para o enchimento de grãos na presença e na ausência de $\mathrm{N}$ (HIREL et al., 2007). Assim, a atividade da enzima GS deve ser considerada na seleção de genótipos de milho mais eficientes no uso de $\mathrm{N}$.

Os ganhos indiretos nas eficiências de $\mathrm{N}$ com seleção realizada nas atividades da NR e GS, em baixo, foram estimadas com intuito de entender melhor a influência dessa seleção na eficiência no uso de $\mathrm{N}$ e em seus componentes. As estimativas dos ganhos indiretos (\%) em EUsN e seus componentes por meio da seleção em atividade da NR foram negativos (Tabela 5). Isso era esperado, pois a atividade da NR correlacionou negativamente com a eficiência no uso de nitrogênio e seus componentes.

Tabela 5 - Estimativas dos ganhos (\%) nas eficiências na absorção (EAbN, mg mg ${ }^{-1}$ ), na utilização (EUtN, $\mathrm{mg} \mathrm{mg}^{-1}$ ) e no uso de $\mathrm{N}$ (EUsN, mg mg-1) por meio da seleção indireta na atividade das enzimas nitrato redutase (NR, $\mu$ moles de $\mathrm{NO}_{2}{ }_{2}^{-1} \mathrm{MF} \mathrm{h}^{-1}$ ) e glutamina sintetase (GS, $\mu$ moles GGH g ${ }^{-1} \mathrm{MF} \mathrm{min}^{-1}$ ) milho em baixo $\mathrm{N}$

\begin{tabular}{lrrr}
\hline Ganho indireto $(\%)$ & EAbN & EUtN & EUN \\
\hline NR & $-18,63$ & $-35,01$ & $-23,88$ \\
GS & 24,01 & 21,16 & 24,93 \\
\hline
\end{tabular}

Em relação à atividade de GS, quando foi considerada a seleção indireta via atividade dessa enzima, os ganhos estimados foram positivos e de magnitude elevada. Assim, é provável que a enzima GS seja um ponto chave no controle do crescimento e da produtividade das plantas (MIFLIN; HABASH, 2002). Além disso, esses ganhos indicam que a seleção para atividade de GS possibilita a seleção indireta e precoce de genótipos de milho eficientes no uso de $\mathrm{N}$, o que maximiza a eficácia e, consequentemente, os ganhos com a seleção nos programas de melhoramento genético de milho para eficiência no uso de $\mathrm{N}$ e seus componentes.

\section{CONCLUSÕES}

1.Em alto nível de nitrogênio, a eficiência de absorção de nitrogênio é eficiente para discriminar genótipos de milho eficientes no uso de nitrogênio;

2.Em baixo nitrogênio, as eficiências na absorção e utilização de nitrogênio são eficientes para discriminar genótipos de milho eficientes no uso de nitrogênio;

3.Em baixo nitrogênio, a atividade de NR não é um bom parâmetro fisiológico para discriminar genótipos de milho eficientes no uso de nitrogênio;
4.Em baixo nitrogênio, a seleção na atividade da enzima glutamina sintetase possibilita a seleção indireta de genótipos de milho eficientes no uso de nitrogênio.

\section{AGRADECIMENTOS}

Ao CNPq, CAPES e FAMING pelo suporte financeiro para a condução dos experimentos.

\section{REFERÊNCIAS}

AHLGREN, S. et al. Ammonium nitrate fertilizer production based on biomass - environmental effects from a life cycle perspective. Bioresource Technology, v. 99, n. 17, p. 80348041, 2008.

ARAÚJO,L.A.N.;FERREIRA, M.E.; CRUZ, M. C.P. Adubação nitrogenada na cultura do milho. Pesquisa Agropecuária Brasileira, v. 39, p. 771-777, 2004.

BARTLETT, M. S. Properties of sufficiency and statistical tests. Proceedings of the royal society of London, v. 160, n. 901, p. 268-282, 1937.

BERTIN, P.; GALLAIS, A. Genetic variation for nitrogen use efficiency in a set of recombinant inbred lines: I. Agrophysiological results. Maydica, v. 45, n. 1, p. 53-66, 2000.

BREMNER, J. M.; MULVANEY, C. S. Nitrogen total. In: PAGE, A. L.; MILLER, R. H.; KEENEY, D. R. Methods of soil analysis. Madison: Soil Science Society of America, 1982. p. 595-624.

CHUN, L. et al. Genetic analysis of maize root characteristics in response to low nitrogen stress. Plant Soil, v. 276, n. 1/2, p. 369-382, 2005.

COQUE, M.; GALLAIS, A. Genetic variation for nitrogen remobilization and postsilking nitrogen uptake in maize recombinant inbred lines: Heritabilities and correlations among traits. Crop Science, v. 47, n. 5, p. 1787-1796, 2007.

CRUZ, C. D. Princípios de Genética Quantitativa. Viçosa: Viçosa, 2005. 394 p.

DA MATTA F. M.; AMARAL, J. A. T.; RENA, A. B. Growth periodicity in trees of Coffea arabica $\mathrm{L}$. in relation to nitrogen supply and nitrate reductase activity. Field Crops Research, v. 60, n. 3 , p. 223-229, 1999.

DoVALE, J. C. et al. Efeitos gênicos de caracteres associados à eficiência no uso de nitrogênio em milho. Pesquisa Agropecuária Brasileira, v. 47, n. 3, p. 385-392, 2012 b.

DoVALE, J. C.; DeLIMA, R. O.; Fritsche-Neto, R. Breeding for nitrogen use efficiency. In: Fritsche-Neto, R.; Borém, A. Plant breeding for stress tolerance. Berlin: Editora Springer, 2012a. cap. 4, p.53-66.

DUVICK, D. N. What is yield? In: Edmeades, G. O. et al. (Ed.), Developing Drought and Low N-tolerant maize. México: CIMMYT, 1997. p. 332-335. 
ELLIOTT, W. H. Isolation of glutamine synthetase and glutamotransferase from green peas. Journal of Biological Chemistry, v. 201, p. 661-672, 1953.

FOOD AND AGRICULTURE ORGANIZATION OF THE UNITED NATIONS. Maize, rice and wheat: area harvested, production quantity, yield. Food and Agriculture Organization of the United Nations, Statistics Division, 2001.

FRITSCHE-NETO, R. et al. Herança de caracteres associados à eficiência de utilização do fósforo em milho. Pesquisa Agropecuária Brasileira, v. 45, n. 5, p. 465-471, 2010.

GALLAIS, A.; HIREL, B. An approach to the genetics of nitrogen of use efficiency in maize. Journal of Experimental Botany, v .55, n. 396, p. 295-306, 2004.

HEINZ, R. et al. Seleção de progenies de meios-irmãos de milho para eficiência no uso de nitrogênio. Revista Ciência Agronômica, v. 43, n. 4, p. 731-739, 2012.

HIREL, B.; BERTIN, P.; QUILLÉRÉ, I. Towards a better understanding of the genetic and physiological basis for nitrogen use efficiency in maize. Plant Physiology, v. 125, n. 3, p. $1258-1270,2001$.

HIREL, B. et al. The challenge of improving nitrogen use efficiency in crop plants: towards a more central role for genetic variability and quantitative genetics within integrated approaches. Journal of Experimental Botany, v. 58, n. 9, p. 2369-2387, 2007.

KAWACHI, T. et al. Role of xylem sap nitrate in regulation of nitrate reductase gene expression in leaves of barley (Hordeum vulgare L.) seedlings. Soil Science and Plant Nutrition, v. 48, p. 79-85, 2002.

LEA, P. J.; AZEVEDO, R. A. Nitrogen use efficiency 2. Amino acid metabolism. Annals of Applied Biology, v. 151, n. 3, p. 269-275, 2007.

LEA, P. J. Primary nitrogen metabolism. In: DEY, P. M.; HARBORNE, J. B. Plant biochemistry. New York: Academic Press, 1997. p. 273-313.

NELSON, D. L.; COX, M. M. Princípios de bioquímica de Lehninger. 5. ed. São Paulo: Artmed, 1995. 1273 p.

LEMAIRE, G.; GASTAL, F. N. N uptake and distribution in plant canopies. In: LEMAIRE, G. Diagnosis of the nitrogen status in crops. Berlin: Springer, 1997. p. 3-43.

MACHADO, A. T.; SODEK, L.; FERNANDES, M. S. Npartitioning, nitrate reductase and glutamine synthetase activities in two contrasting varieties of maize. Pesquisa Agropecuária Brasileira, v. 36, n. 2, p. 249-256, 2001.

MAIA, C. et al. The difference between breeding for nutrient use efficiency and for nutrient stress tolerance. Crop Breeding and Applied Biotechnology, v. 11, n. 3, p. 270-275, 2011.
MAJEROWICZ, N. et al. Estudo da eficiência de uso do $\mathrm{N}$ em variedades locais e melhoradas de milho. Revista Brasileira Botânica, v. 25, p. 129-136, 2002.

MIFLIN, B. J.; HABASH, D. Z. The role of glutamine synthetase and glutamate dehydrogenase in nitrogen assimilation and possibilities for improvement in the nitrogen utilization of crops. Journal of Experimental Botany, v. 53, n. 370, p. 979-987, 2002.

MOLL, R. H.; KAMPRATH, E. L.; JACKSON, A. Analysis and interpretation of factors which contribute to efficiency of nitrogen utilization. Agronomy Journal, v. 74, n. 3, p. 562-564, 1982.

MONNEVEUX, P. et al. Population density and low nitrogen affects yield - associated traits in tropical maize. Crop Science, v. 45, p. 535-545, 2005.

PIMENTEL-GOMES, F. Curso de estatística experimental. 15. ed. Piracicaba: Fealq, 2009. 451 p.

PRESTERL, T. et al. Improving nitrogen-use efficiency in European maize: Estimation of quantitative genetic parameters. Crop Science, v. 43, n. 4, p. 1259-1265, 2003.

PURCINO, A. A. C. et al. Atividade da redutase do nitrato em genótipos antigos e modernos de milho, cultivados sob dois níveis de nitrogênio. Revista Brasileira de Fisiologia Vegetal, v. 6, n. 1, p. 41- 46, 1994.

RAMALHO, M. A. P.; FERREIRA, D. F.; OLIVEIRA, A. C. Experimentação em Genética e melhoramento de plantas. 3 . ed. Lavras: UFLA, 2012. 328p.

SAS INSTITUTE. SAS/STAT: user's guide. Version 9.1. Cary: SAA Institute, 2003.

SOARES, M. O. et al. Parâmetros genéticos de uma população de milho em níveis contrastantes de nitrogênio. Revista Ciência Agronômica, v. 42, n. 1, p. 168-174, 2011.

SOUZA, L. V. et al. Genetic control of grain yield and nitrogen use efficiency in tropical maize. Pesquisa Agropecuária Brasileira, v. 43, n. 11, p. 1517-1523, 2008.

TAIZ, L.; ZEIGER, E. Plant Physiology. 5. ed. Sunderland: Sinauer Associates, 2010. 764 p.

UNNO, H. et al. Atomic Structure of Plant Glutamine Synthetase. The Journal of Biological Chemistry, v. 281, n. 39, p. 29287-29296, 2006.

URIBELARREA, M.; MOOSE, S. P.; BELOW, F. E. Divergent selection for grain protein affects nitrogen use in maize hybrids. Fields Crops Research, v. 100, n. 1, p. 82-90, 2007.

WALKER, T. C.; JARAMILHO, R.; LYNCH, J. P. Architectural tradeoffs between adventitious and basal roots for phosphorus acquisition. Plant Soil, v. 279, n. 1/2, p. 347-366, 2006. 